\title{
A $\sigma$-Convergence Model for Analyzing the Balance of Insurance Industry in China
}

\author{
Zeyun Yang $\mathbb{D},^{1,2}$ Wendong Xiao $\mathbb{D D}^{2}$, and Qiaoling Fu $\mathbb{i D}^{2}$ \\ ${ }^{1}$ School of Insurance Economics, University of International Business and Economics, Beijing 100029, China \\ ${ }^{2}$ Management College of Beijing Union University, Beijing Union University, Beijing 100101, China \\ Correspondence should be addressed to Wendong Xiao; gltwendong@buu.edu.cn
}

Received 22 July 2021; Accepted 16 August 2021; Published 15 September 2021

Academic Editor: Daqing Gong

Copyright (c) 2021 Zeyun Yang et al. This is an open access article distributed under the Creative Commons Attribution License, which permits unrestricted use, distribution, and reproduction in any medium, provided the original work is properly cited.

There are significant regional differences in the development of China's insurance industry. An important question is that such regional differences are expanding or shrinking? Based on Barrow's economic growth convergence model, this paper uses the $\sigma$ convergence model to analyze the differences in the development of China's insurance industry and its trends. It draws on the statistics data from 1990 to 2020 . The empirical results show that the convergence of China's insurance development is not obvious before 2006, but it shows a significant convergence after 2006. And, there are some differences between the Eastern, the Central, and the Western. Furthermore, when considering the spatial correlation, the convergence of insurance development among provinces in China is more obvious. This shows that the flowing of capital, technology, and labor force between regions may be beneficial to the balanced development of insurance among the regions.

\section{Introduction}

With the rapid growth of China's economy, China's insurance industry has also experienced rapid development. Since China's insurance business resumed in 1980, the insurance premium has grown rapidly from 460 million yuan in 1980 to 4.53 trillion yuan in 2020, with an annual compound growth rate of nearly $30 \%$. The insurance penetration and the insurance density have increased from almost zero to $4.5 \%$ and 3,233 yuan, respectively, in 2020 . The share of the world market has also grown almost from zero to $12.4 \%$ in 2020 . However, China is a vast country with large regional differences. While China's insurance industry has made brilliant achievements in the total volume, it also presents a large regional unbalance [1-5]. In 2020, the region with the highest density was 9.65 times that with the lowest density, according to the National Bureau of Statistics. The regional unbalance in the development of insurance industry is not only unfavorable to the formation of effective market competition pattern but also unfavorable to the diversification of insurance market operation risks. And, it will restrict the ability of insurance market opening to the outside world and even aggravate the unbalance of regional economic development [2].

The report of the 19th National Congress of the Communist Party of China pointed out that "China's social productivity has increased significantly on the whole. The more prominent problem is that our development is unbalanced and inadequate." Then, is such unbalance in China's insurance industry development gradually expanding or shrinking? The economic growth convergence theory of the neoclassical school of economics can well answer this question: if the development of China's insurance industry exhibits convergence, it indicates a shrinking trend in the unbalanced development of our insurance industry; otherwise, the unbalance in our insurance industry development continues to expand.

The neoclassical economic growth theory thinks that due to the diminishing marginal return of capital, as the capital stock grows, the economic or financial growth of the country or region will slow down, or even stop. At the same time, due to the diminishing marginal return of capital, the backward areas will have faster economic or financial growth than developed areas, that is, there is a phenomenon of 
convergence in economic or financial development. Baumol [6] studied and analyzed the per capita income data of 16 countries from 1870-1978 for more than 100 years, finding obvious economic convergence in these countries. Although many scholars subsequently questioned the convergence hypothesis of neoclassical economics [7] and even many empirical studies have shown the inconsistency among the actual situation and the convergence theory, the unique charm of the economic growth convergence hypothesis still attracts many scholars to conduct more extensive and detailed research studies about economic growth convergence, with a view to extending and perfecting the theory of economic growth convergence.

Since the modern neoclassical school of economics put forward the hypothesis of economic growth convergence, researchers have done more and more research studies in this regard [8-15]. Economic growth convergence includes $\sigma$-convergence, $\beta$-convergence, and club convergence. The socalled economic growth $\beta$ convergence means there is negative correlation between the growth rate of economic development and its initial level, that is, relatively backward regions have higher economic growth rate than relatively rich regions [16]. In actual research, scholars further divide $\beta$ convergence into absolute $\beta$ convergence and conditional $\beta$ convergence. The former means that the economic growth rate is only related to the initial level, while conditional convergence examines not only the economic growth rate and the initial level but also other factors such as institutional environment and resource endowments. Since conditional convergence can consider factors such as institutional environment and resource endowments, it is often used to analyze the factors influencing economic growth convergence. On this basis, policy recommendations of reducing the economic growth gap between regions are proposed. Exactly because of this, domestic and foreign scholars' research on convergence in the insurance industry development is absolutely dominated by $\beta$ convergence. Researchers mostly adopt analysis methods of Barro and Sala I. Martin [17], use per capita insurance premium data, and take economic growth models in regression analysis to test and analyze the domestic insurance development convergence. $\sigma$-convergence means that the standard deviation of the economic development level between different countries or regions tends to decrease over time. Compared with $\beta$ convergence analysis which is more susceptible to the selected "initial stage," $\sigma$-convergence focuses on changes in the development level differences between countries or regions during the entire research period, which is not easily susceptible to the initial research stage. Therefore, this paper analyzes $\sigma$-convergence of our insurance industry development from a spatial perspective to determine the equilibrium status in the development of our regional insurance market. However, we cannot analyze the reasons that cause the convergence using the $\sigma$-convergence model.

\section{Research Model}

According to Barro and Sala I. Martin [17], $\sigma$-convergence studies the logarithm dispersion of per capita income between different economic systems. If it tends to decrease over time, it indicates presence of $\sigma$-convergence. To describe and analyze the changes in the differences of the insurance development level among the domestic provinces, this paper uses the standard deviation of logarithm (in $\ln Y_{i t}$ ) of the actual per capita insurance premium in each province to reflect changes in the differences. The calculation formula is as follows:

$$
\begin{aligned}
y_{i t} & =\ln \left(Y_{i t}\right), \\
\bar{y}_{t} & =\frac{1}{N} \sum_{i=1}^{N} y_{i t}, \quad i=1,2, \ldots, N ; t=1,2, \ldots, T, \\
\sigma_{t} & =\sqrt{\frac{1}{N-1} \sum_{i=1}^{N}\left(y_{i t}-\bar{y}_{t}\right)^{2} .}
\end{aligned}
$$

When $\sigma_{t}>\sigma_{t-1}$, it means that there is $\sigma$-convergence in regional insurance development of China.

The logarithmic per capita insurance premium of each province of region in each year is regressed by ordinary least squares (ols) constant term:

$$
y_{i t}=\bar{y}_{t}+\varepsilon_{i t},
$$

where $i=1,2, \ldots, N$ and $t=1,2, \ldots, T$. It can be seen that the variance of the residual term in the regression of equation (2) has an estimated value of $\sigma_{t}^{2}$. In the next step, the square root of the variance can be calculated, and the standard deviation $\sigma_{t}$ can also be obtained.

However, estimation of $\sigma_{t}^{2}$ using the residual term $\varepsilon_{i t}$ of equation (2) means irrelevant insurance development between the provinces. Obviously, this does not comply with the reality [18-21]: Firstly, according to the First Law of Geography, "everything is related to everything else, but near things are more related than distant things." Therefore, there are all kinds of connections in the insurance development among the provinces, and the closer provinces have closer connections. Secondly, it is not independent in the actual economic and financial operation among the provinces. In the literatures, the technology spillover is often regarded as an important mechanism to promote the economic convergence. In the insurance development, the influence of the insurance awareness among residents of various provinces, especially among residents of the neighboring provinces, and the spreading of the insurance management skills are also the important mechanisms to promote the insurance development. Hence, the hypothesis in equation (2) that the insurance development of each region is irrelevant deviates from the reality. Based on this, there may be deviations in the analysis on insurance development convergence of each province. Here, it is necessary to introduce the correlation between regions so that correct judgment on the insurance development convergence in various provinces can be made.

In view of this, this paper considers the spatial correlation based on the ordinary least squares (ols) regression and uses the spatial measurement regression to more accurately analyze the convergence in the domestic insurance industry development. For spatial correlation, based on the fact that there are different variables reflecting the 
correlation between institutions or regions in the model, models can be divided into the spatial lag model and spatial error model, that is,

$$
\begin{aligned}
y_{i t} & =\rho \omega y_{i t}+\bar{y}_{t}+\varepsilon_{i t}, \\
y_{i t} & =\bar{y}_{t}+\varepsilon_{i t}, \\
\varepsilon_{i t} & =\lambda \omega \varepsilon_{i t}+\mu_{i t},
\end{aligned}
$$

where the spatial lag model assumes that the insurance industry development in other regions will affect the insurance industry development in the local region; the spatial error model assumes that other factors in other regions will impact the insurance industry development of the local region.

\section{Result Analysis}

3.1. Data Source and Description. Considering the data's availability, this paper collects the relevant data in 1990 2020 to study the convergence of our interprovincial actual insurance density (that is, per capita insurance premium) in 31 years. The insurance density of the province is equal to the ratio of the actual insurance premium of the province to the total population of the province at the end of the year, and the insurance premium is deflated based on the price in 1978. The data in the paper comes from the "Compilation of 60-Year Statistical Data of New China" and the "China Insurance Yearbook" of the years. Table 1 below shows the basic information about the actual insurance premium in each year.

The spatial weight matrix herein is a neighbor-order matrix generated based on the China Geographic Vector Map of the National Basic Geographic Information System, where Hainan Island is an independent island, which is set to be adjacent to Guangdong Province here.

3.2. Empirical Results. According to Tobler [22] First Law of Geography, everything is related to everything else, but near things are more related than distant things. Based on this, we believe that certain correlation exists between the provincelevel regions in domestic insurance development, and there is stronger relevance in the neighboring provinces on the insurance development. Due to the complexity of spatial correlation, there are many methods and indicators to measure spatial correlation, among which the Moran index is more prevalent [23]:

$$
I=\frac{\sum_{i=1}^{n} \sum_{j=1}^{n} w_{i j}\left(x_{i}-\bar{x}\right)\left(x_{j}-\bar{x}\right)}{s^{2} \sum_{i=1}^{n} \sum_{j=1}^{n} w_{i j}}
$$

where $s^{2}=\left(\sum_{i=1}^{n}\left(x_{i}-\bar{x}\right)^{2} / n\right)$ is the sample variance, $w_{i j}$ is the $(i, j)$ element of the spatial weight matrix used to measure the distance between the province $i$ and the province $j$, and $\sum_{i=1}^{n} \sum_{j=1}^{n} w_{i j}$ is the sum of all the spatial weights. If the spatial weight matrix is row-normalized, then $\sum_{i=1}^{n} \sum_{j=1}^{n} w_{i j}=n$. At this time, Moran index $I$ can be written as

$$
I=\frac{\sum_{i=1}^{n} \sum_{j=1}^{n} w_{i j}\left(x_{i}-\bar{x}\right)\left(x_{j}-\bar{x}\right)}{\sum_{i=1}^{n} \sum_{j=1}^{n}\left(x_{i}-\bar{x}\right)^{2}}
$$

If the spatial weight matrix is a row-normalized matrix, the value of Moran index $I$ is between -1 and 1 . A value greater than 0 indicates positive autocorrelation, that is, high value is adjacent to high value, while low value is adjacent to low value. On the contrary, a value smaller than 0 indicates negative correlation, that is, high value is adjacent to low value. If the Moran index $I$ approaches 0 , it means that the spatial distribution is random and there is no spatial correlation.

In this paper, the weight matrix adopts the simple geographic adjacency weight matrix, that is, for the 31 provinces in Mainland China, if they are geographically adjacent, the corresponding weight is 1 ; otherwise, it is 0 . In addition, for Hainan Province which is not adjacent to any other province, to facilitate calculation, it is assumed that Hainan Province is adjacent to its nearest Guangdong Province. At the same time, row normalization is performed on the weight matrix, that is, the sum of each row in the matrix is 1 .

As shown in Table 2 below, the results show significantly positive Moran index of insurance density in each province from 1990 to 2017, indicating that there is significant spatial positive correlation in the provincial insurance development.

\section{Discussions}

Figure 1 below is a time series diagram regarding the standard deviation of the logarithm of the per capita insurance density in each province without considering spatial correlation. It can be seen that, from the national perspective, before 2006, the logarithmic variance of our interprovincial insurance density waved between 0.49 and 0.68 and did not show a significant downward trend, that is, our interprovincial insurance development did not reveal obvious convergence. After 2006, the logarithmic variance of insurance density dropped from 0.60 in 2006 to 0.22 in 2020 and exhibited a clear downward trend, that is, after 2006, interprovincial insurance development displayed obvious convergence in our country.

Furthermore, we divide the country into the Eastern, Central, and Western regions and analyze $\sigma$-convergence of the insurance development among the provinces and cities in the Eastern, Central, and Western. It can be seen that, before 1998, the insurance density logarithm among the provinces in the Eastern region showed a significant increase, increased from 0.32 in 1990 to 0.67 in 1998, while between 1998 and 2005, the logarithm variance of insurance density in the Eastern region showed a relatively stable, waved between 0.62 and 0.72. And, after 2006, the Eastern provinces exhibited obvious convergence, dropped from 0.62 in 2006 to 0.21 in 2020, while the Central and the Western provinces are relatively stable in the research span.

Finally, we further consider $\sigma$-convergence with the spatial correlation. As mentioned above, the insurance 
TABLE 1: Statistics on the actual insurance premium of each province from 1990 to 2017 (unit: 100 million yuan).

\begin{tabular}{|c|c|c|c|c|c|c|}
\hline Year & Minimum & Maximum & Median & Mean & Standard deviation & Total premium \\
\hline 1990 & 0.031 & 8.340 & 1.752 & 2.269 & 1.827 & 70.352 \\
\hline 1991 & 0.032 & 10.666 & 2.182 & 2.895 & 2.414 & 89.731 \\
\hline 1992 & 0.039 & 15.851 & 2.965 & 4.186 & 3.633 & 129.773 \\
\hline 1993 & 0.052 & 19.562 & 3.362 & 4.554 & 4.156 & 141.161 \\
\hline 1994 & 0.048 & 21.422 & 3.122 & 4.408 & 4.245 & 136.657 \\
\hline 1995 & 0.073 & 21.400 & 3.329 & 4.696 & 4.320 & 145.578 \\
\hline 1996 & 0.076 & 21.678 & 3.996 & 5.670 & 4.939 & 175.760 \\
\hline 1997 & 0.091 & 24.189 & 5.508 & 7.956 & 6.872 & 246.622 \\
\hline 1998 & 0.104 & 27.855 & 6.196 & 9.027 & 7.318 & 279.847 \\
\hline 1999 & 0.130 & 35.720 & 6.742 & 10.548 & 8.747 & 326.973 \\
\hline 2000 & 0.162 & 44.658 & 9.297 & 12.239 & 10.124 & 379.415 \\
\hline 2001 & 0.182 & 56.596 & 9.870 & 15.557 & 13.890 & 482.273 \\
\hline 2002 & 0.201 & 72.588 & 15.864 & 22.683 & 19.641 & 703.175 \\
\hline 2003 & 0.234 & 87.359 & 20.631 & 28.453 & 24.256 & 882.031 \\
\hline 2004 & 0.315 & 95.685 & 22.848 & 30.537 & 25.758 & 946.632 \\
\hline 2005 & 0.338 & 107.594 & 26.251 & 34.246 & 30.081 & 1061.614 \\
\hline 2006 & 0.413 & 128.955 & 29.931 & 38.514 & 32.677 & 1193.944 \\
\hline 2007 & 0.543 & 163.960 & 31.507 & 45.352 & 38.867 & 1405.913 \\
\hline 2008 & 0.622 & 215.225 & 48.058 & 59.627 & 49.142 & 1848.444 \\
\hline 2009 & 0.773 & 237.219 & 53.636 & 68.343 & 56.291 & 2118.646 \\
\hline 2010 & 0.944 & 265.189 & 64.022 & 85.219 & 68.267 & 2641.776 \\
\hline 2011 & 1.345 & 279.463 & 60.835 & 80.707 & 66.515 & 2501.916 \\
\hline 2012 & 1.646 & 291.896 & 63.021 & 84.822 & 69.641 & 2629.471 \\
\hline 2013 & 1.922 & 319.924 & 69.331 & 92.940 & 75.084 & 2881.133 \\
\hline 2014 & 2.103 & 385.962 & 78.581 & 106.017 & 87.303 & 3286.542 \\
\hline 2015 & 2.822 & 457.472 & 95.372 & 125.679 & 102.167 & 3896.057 \\
\hline 2016 & 3.546 & 608.846 & 111.267 & 157.111 & 134.952 & 4870.434 \\
\hline 2017 & 4.394 & 675.231 & 136.315 & 183.071 & 155.498 & 5675.209 \\
\hline 2018 & 5.139 & 716.529 & 138.133 & 188.021 & 155.574 & 5840.621 \\
\hline 2019 & 5.524 & 820.543 & 142.132 & 205.121 & 174.413 & 6366.826 \\
\hline 2020 & 5.799 & 823.430 & 143.863 & 212.371 & 178.851 & 6952.425 \\
\hline
\end{tabular}

development in all the provinces is significant spatial correlate. Therefore, the $\sigma$-convergence analysis without considering the spatial correlation would be inaccurate. We, respectively, adopt the spatial autocorrelation model (sar), the spatial error model (sem), and the model that considering the spatial autocorrelation and the spatial error term at the same time (sae). Figures 2-5 show the standard deviations of the spatial models of the national, Eastern, Central, and Western provinces, respectively. At the same time, we also show the results without considering the spatial correlation (ols) to compare.

It can be seen from Figure 2 that the standard deviation of the spatial error model (sar) is basically the same as that of the ordinary least squares model without considering the spatial correlation, not only the same trend but also the little difference in value. And, the standard deviation of the spatial autocorrelation model is basically the same as that of the model that considering the spatial autocorrelation and the spatial error at the same time (sae). Although the standard deviation of the spatial autocorrelation model has basically the same trend as that of the spatial error model and the ordinary least squares model, the standard deviation value has dropped significantly. This suggests that, after considering the spatial autocorrelation, the divergence of the insurance development among the provinces has decreased significantly. This means that the insurance development in the province can be affected by the neighboring provinces.

Finally, in the regional analysis of the three regions in the Eastern, Central, and Western regions, as shown in Figures 3-5, the standard deviations of regions with or without considering the spatial correlation show great differences:

Firstly, compared with the national model with or without spatial correlation, the standard deviation of the ordinary least square model without the spatial correlation in the Eastern and the Western regions is numerically smaller than that of the model with spatial correlation, while the standard deviation of the model with or without spatial correlation in the Central region has little difference.

Secondly, there is no obvious upward or downward trend in the standard deviation of the ordinary least squares model, and the standard deviation of the spatial error model shows a downward trend after a rising beginning, that is, if we do not consider the spatial correlation, the insurance development of the Western provinces shows no loose or convergence characteristics. However, when considering the spatial correlation, it shows the characteristic of the divergence at the beginning and the convergence finally. 
TABLE 2: Moran index of logarithm of insurance density in each province from 1990 to 2017.

\begin{tabular}{|c|c|c|c|c|c|}
\hline Year & Moran index $I$ & $E(I)$ & $\mathrm{sd}(I)$ & $z$ & $p$ value ${ }^{*}$ \\
\hline 1990 & 0.314 & -0.033 & 0.107 & 3.240 & 0.001 \\
\hline 1991 & 0.369 & -0.033 & 0.108 & 3.734 & $\leq 0.001$ \\
\hline 1992 & 0.409 & -0.033 & 0.108 & 4.098 & $\leq 0.001$ \\
\hline 1993 & 0.324 & -0.033 & 0.107 & 3.340 & 0.001 \\
\hline 1994 & 0.274 & -0.033 & 0.105 & 2.916 & 0.004 \\
\hline 1995 & 0.269 & -0.033 & 0.106 & 2.848 & 0.004 \\
\hline 1996 & 0.205 & -0.033 & 0.106 & 2.253 & 0.024 \\
\hline 1997 & 0.237 & -0.033 & 0.104 & 2.603 & 0.009 \\
\hline 1998 & 0.216 & -0.033 & 0.104 & 2.394 & 0.017 \\
\hline 1999 & 0.192 & -0.033 & 0.104 & 2.157 & 0.031 \\
\hline 2000 & 0.203 & -0.033 & 0.105 & 2.255 & 0.024 \\
\hline 2001 & 0.226 & -0.033 & 0.105 & 2.484 & 0.013 \\
\hline 2002 & 0.242 & -0.033 & 0.105 & 2.626 & 0.009 \\
\hline 2003 & 0.277 & -0.033 & 0.105 & 2.960 & 0.003 \\
\hline 2004 & 0.310 & -0.033 & 0.105 & 3.260 & 0.001 \\
\hline 2005 & 0.271 & -0.033 & 0.104 & 2.929 & 0.003 \\
\hline 2006 & 0.266 & -0.033 & 0.105 & 2.859 & 0.004 \\
\hline 2007 & 0.254 & -0.033 & 0.105 & 2.727 & 0.006 \\
\hline 2008 & 0.226 & -0.033 & 0.105 & 2.461 & 0.014 \\
\hline 2009 & 0.228 & -0.033 & 0.105 & 2.493 & 0.013 \\
\hline 2010 & 0.236 & -0.033 & 0.104 & 2.584 & 0.010 \\
\hline 2011 & 0.234 & -0.033 & 0.105 & 2.531 & 0.011 \\
\hline 2012 & 0.228 & -0.033 & 0.105 & 2.481 & 0.013 \\
\hline 2013 & 0.227 & -0.033 & 0.106 & 2.463 & 0.014 \\
\hline 2014 & 0.221 & -0.033 & 0.105 & 2.420 & 0.016 \\
\hline 2015 & 0.248 & -0.033 & 0.105 & 2.677 & 0.007 \\
\hline 2016 & 0.240 & -0.033 & 0.105 & 2.592 & 0.010 \\
\hline 2017 & 0.256 & -0.033 & 0.106 & 2.738 & 0.006 \\
\hline
\end{tabular}

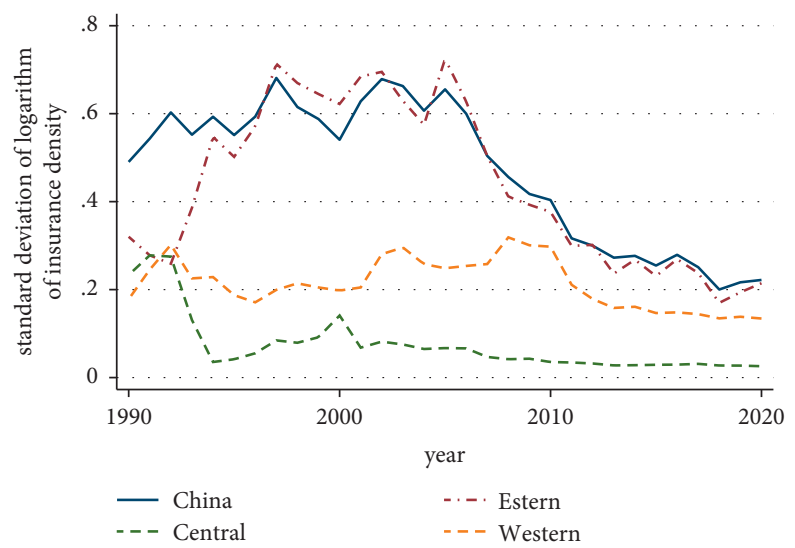

FIgURE 1: Time series diagram on the standard deviation of logarithm of the insurance density in China during 1990-2020.

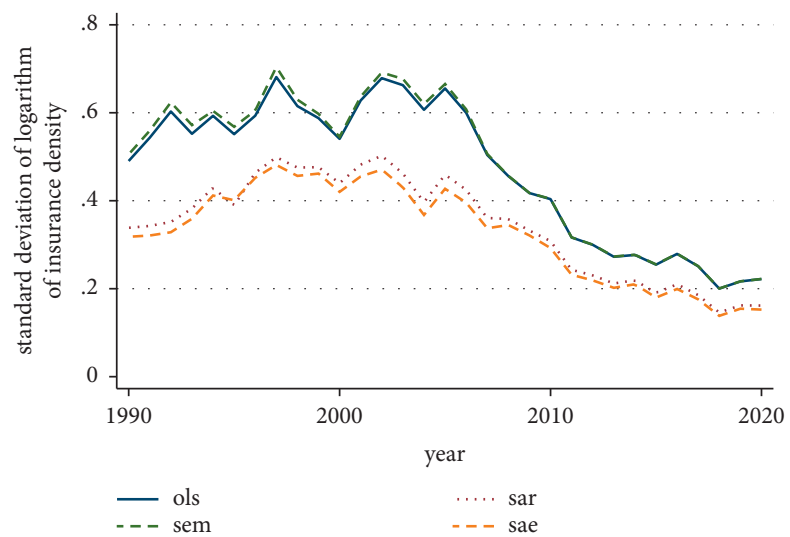

Figure 2: Time series diagram on the standard deviation of logarithm of the insurance density in China during 1990-2020. 


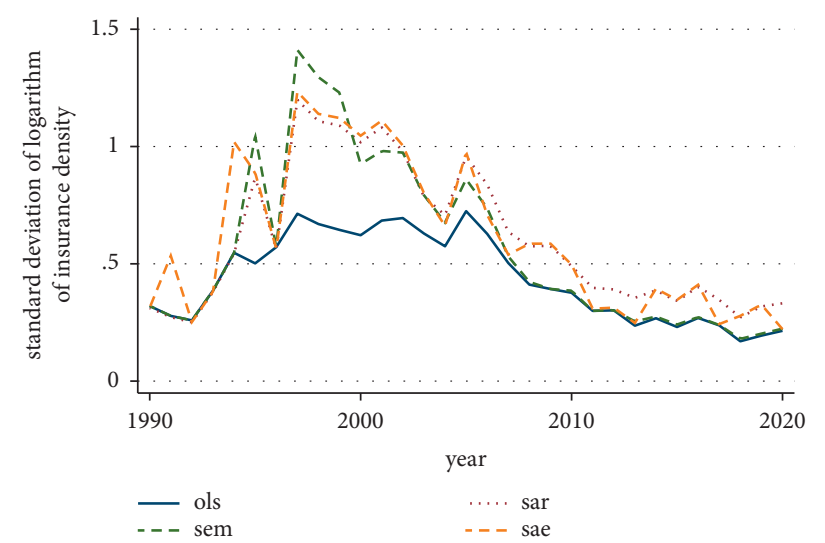

Figure 3: Time series diagram on the standard deviation of logarithm of the insurance density in eastern China during 1990-2020.

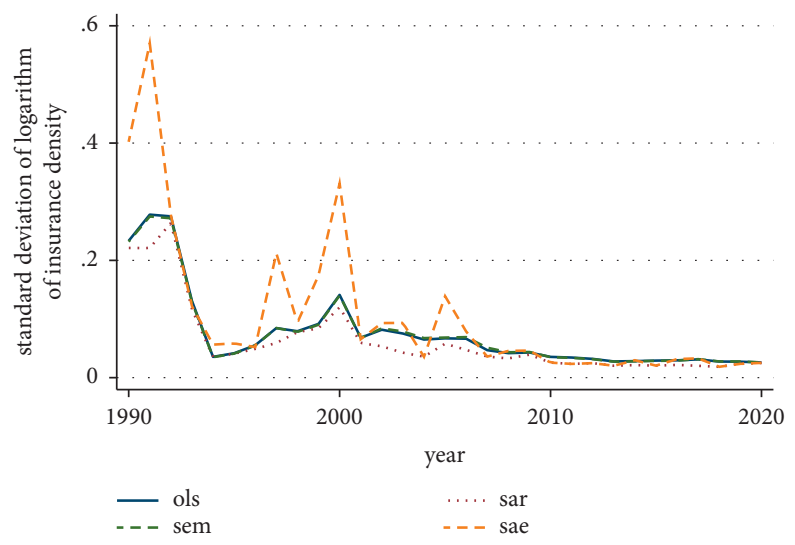

FIgURE 4: Time series diagram on the standard deviation of logarithm of the insurance density in central China during 1990-2020.

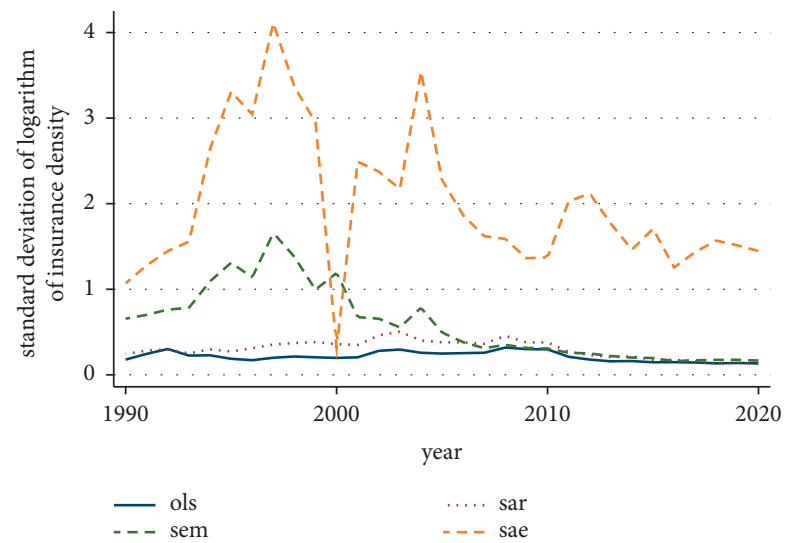

Figure 5: Time series diagram on the standard deviation of logarithm of the insurance density in western China during 1990-2020.

\section{Conclusions}

The balanced development of China's insurance among provinces not only affects the formation of an orderly market competition pattern but also is conducive to the spread of insurance business risks and even affects the balanced development of the interprovincial economy. Based on Barrow's economic growth convergence model, this paper uses the $\sigma$ convergence model to analyze the differences in the development of China's insurance industry and its trends. On the whole, the development of the insurance industry among China's provinces shows the characteristics of $\sigma$-convergence, and we draw the conclusion that the development imbalance of the insurance industry among China's provinces declines. Insurance is one of the effective means of the risk management in social and economic 
development and plays an important role in the loss compensation, the fund financing, and the social management. Therefore, the convergence of the insurance industry is related to the stability of the insurance market and even affects the economic and social development of the whole country. Based on the traditional disregard of the mutual influence of insurance development among regions, this paper uses the method of spatial econometrics to emphasize the spatial correlation of the development of insurance in the different provinces and to analyze and test the convergence of the development of insurance industry in China.

Firstly, according to the First Law of Geography, the insurance development may be relevant among the provinces. This paper calculates the Moran index of the insurance density of the domestic provinces in 1990-2020, and the results indicate that insurance development in domestic provinces is indeed spatially correlated. This means that each province's insurance development is affected by the neighboring insurance development. Therefore, there are deviations in the traditional $\sigma$-convergence analysis, and we should consider $\sigma$-convergence considering the spatial correlation.

Secondly, regardless of whether spatial correlation is considered, on the whole, there has been a $\sigma$-convergence in China's insurance development since 2006, but when considering the spatial correlation, the standard deviation should be lower. It means that the difference of insurance development among provinces should be smaller. Based on the neoclassical economic growth model, the insurance development of a province is only related to the development stage of the insurance industry in the province. However, in actual economic development, the insurance development is affected by many factors. And, according to the neoclassical economic growth model, even if the provinces are independent of each other, the law of diminishing marginal returns will still make insurance development converge. In the real economy, the flow of talent, capital, and technology among provinces will further promote the convergence of insurance between provinces.

Thirdly, the country is divided into three regions: Eastern, Central, and Western. There are some differences when the spatial correlation is considered or not among them. In the Central regions, there are little differences on the convergence between considering the spatial correlation and not considering the spatial correlation. However, in the Eastern and Western regions, when the spatial correlation is excluded, the Eastern region exhibits convergence after 2006, same as the whole country. However, when considering the spatial correlation, convergence is displayed since 1998. For the Western region, when the spatial correlation is excluded, no convergence is shown during the entire inspection period, but when considering the spatial correlation, it also displays convergence since 1998.

It must be pointed that all the results are based on the hypothesis that the spatial matrix is spatially contiguous, that is, we believe that the spatial effect only occurred between the neighbor provinces. But in reality, there are many communications among the different provinces.

\section{Recommendations and Enlightenment}

Based on the results, we can get some recommendations and enlightenments:

Firstly, on the whole, regardless of whether the spatial correlation is considered, insurance industry development in domestic provinces tends to diverge at the beginning and then converge since 1990 . However, when considering the spatial correlation, imbalance in insurance industry development among the provinces is greatly reduced. It suggests that the government can lower the interprovincial insurance technical barriers and promote and encourage the flow of insurance talents, capital, and technology, thereby enhancing the effective interaction of insurance industry between the provinces, reducing the differences in the insurance development level between the provinces.

Secondly, there are many differences in convergence between the Eastern, Central, and Western regions. When the spatial correlation is not considered, there is unobvious convergence in the insurance industry development in the Central and the Western provinces, while the Eastern provinces exhibit the characteristics of first divergence and then convergence. When considering spatial correlation, the Eastern and the Western provinces have shown convergence in recent years. Therefore, in the Eastern and Western provinces, policy makers should pay more attention to strengthening the mutual communication and exchanges in insurance development among the provinces to further strengthen the mutual influence between insurance development, thereby enhancing the convergence of insurance development and reducing the unbalanced insurance development among the provinces.

Finally, the convergence characteristics of the economic growth according to the neoclassical economics have been verified in the insurance field of our country. According to the neoclassical growth theory, the gap in per capita output or income among the countries or regions is a result of different capital-labor ratios: if the savings rate remains unchanged, under the lower initial capital-labor ratio of a country or region, the labor-capital ratio grows faster, so the poorer countries (regions) will grow faster than the richer countries (or regions). This law has been verified in our insurance industry. Hence, for the insurance companies, in terms of the future regional development and layout, they can increase investment in those provinces that the insurance development is relatively slow at present so that it is possible to achieve the faster growth.

\section{Data Availability}

The data in the paper comes from the "Compilation of 60Year Statistical Data of New China" and the "China Insurance Yearbook" of the years.

\section{Conflicts of Interest}

The authors declare that they have no conflicts of interest regarding the publication of this paper. 


\section{Acknowledgments}

This work was supported by Beijing Municipal Philosophy and Social Science Planning Office "Research on the Coordinated Development of Beijing-Tianjin-Hebei Financial Agglomeration and Industrial Structure Upgrading" (16YJB037) and the Academic Research Projects of Beijing Union University (no. XP202012). Thanks are due to the corresponding author.

\section{References}

[1] S. Jiang, Research on Organizational Optimization of China's Insurance Industry, China Social Science Press, Beijing, China, 2003, in Chinese.

[2] J. Zhu, B. Wang, and Li Yun, "Research on spatial distribution of China's insurance industry," Insurance Studies, vol. 7, no. 7, pp. 54-57, 2005, in Chinese.

[3] W. Huang, "Research on regional difference in insurance market of China," Finance \& Economics, vol. 216, no. 3, pp. 111-116, 2006, in Chinese.

[4] Z. Xiao, "On regional equilibrium of insurance market: based on the theory and practice of the insurance demand," Journal of Financial Research, vol. 324, pp. 181-190, 2007, in Chinese.

[5] C. Li, "On spatial inequality and polarization of insurance development in China-based on the contrastive analysis between non-life insurance and life insurance from 1998 to 2010," Collected Essays on Finance and Economics, vol. 2, no. 171, pp. p64-70, 2013, in Chinese.

[6] W. J. Baumol, "Productivity growth, convergence and welfare: what the long-run data show," American Economic Review, vol. 76, pp. 1072-1085, 1986.

[7] J. B. De Long, "Productivity growth, convergence, and welfare: comment," American Economic Review, American Economic Association, vol. 78, no. 5, pp. 1138-1154, 1988.

[8] M. Pagano, "Financial markets and growth," An overview, European Economic Review, vol. 37, no. 2-3, pp. 613-622, 1993.

[9] J. Cummins, "Convergence in wholesale financial services: reinsurance and investment banking," The Geneva Papers on Risk and Insurance-Issues and Practice, vol. 30, no. 2, pp. 187-222, 2005.

[10] G. Zhu and J. Yu, "Is provincial economic growth convergent in China?" China Economic Quarterly, vol. 13, no. 3, pp. 1171-1194, 2014, in Chinese.

[11] M. T. Borsi and N. Metiu, "The evolution of economic convergence in the European Union," Empirical Economics, vol. 48, no. 2, pp. 657-681, 2015.

[12] G. Xue, R. Yixin, L. Xin, and Z. Xiaoyan, "Multiple spillovers of economic policy uncertainty: a transnational analysis," Economic Computation and Economic Cybernetics Studies and Research, vol. 54, no. 2, pp. 95-112, 2020.

[13] C. Y. Park and R. V. Mercado Jr., "Economic convergence, capital accumulation, and income traps: empirical evidence," Review of Income and Wealth, vol. 66, no. 1, pp. 26-58, 2020.

[14] O. Sofía, B. M. Lisana, V. Hernán, and B. G. Maria, "A regional kohonen Map of financial inclusion and related macroeconomic variables," Economic Computation and Economic Cybernetics Studies and Research, vol. 54, no. 3, pp. 179-195, 2020.

[15] L. L. Zhang and H. K. Kim, "The influence of financial service characteristics on use intention through customer satisfaction with mobile fintech," Journal of System and Management Sciences, vol. 10, no. 2, pp. 82-94, 2020.

[16] A. T. Young, M. J. Higgins, and D. Levy, "Sigma convergence versus beta convergence: evidence from U.S. county-level data," Journal of Money, Credit and Banking, vol. 40, no. 5, 2008.

[17] R. J. Barro and X. Sala-I-Martin, "Convergence," Journal of Political Economy, vol. 100, no. 2, pp. 223-251, 1992.

[18] L. Anselin, Spatial Econometrics: Methods and Models, Kluwer Academic Publishers, Dordrecht, Netherlands, 1988.

[19] E. Shehata and S. FMickaiel, "SPREGDPD: stata module to estimate spatial panel arellano-bond linear dynamic regression: lag \& durbin models," 2013, https://EconPapers.repec. org/RePEc:boc:bocode:s457506.

[20] D. P. Kingma, J. Ba, and Adam, "A method for stochastic optimization," 2014, https://arxiv.org/abs/1412.6980.

[21] M. Liu and S. Wang, "A study on $\beta$ convergence and spatial dependence of China's manufacturing industry from the global financial crisis to China's new normal," The Journal of Quantitative \& Technical Economics, vol. 35, no. 2, pp. 3-23, 2018, in Chinese.

[22] W. R. Tobler, "A computer movie simulating urban growth in the detroit region,” Economic Geography, vol. 46, pp. 234-240, 1970.

[23] P. A. P. Moran, "Notes on continuous stochastic phenomena," Biometrika, vol. 37, no. 1-2, pp. 17-23, 1950. 